\title{
Stress in psychiatrists: coping with a decade of rapid change
}

\author{
Shanaya Rathod, Minal Mistry, ${ }^{2}$ Ben Ibbotson, ${ }^{2}$ David Kingdon ${ }^{3}$
}

The Psychiatrist (2011), 35, 130-134, doi: 10.1192/pb.bp.110.030858

${ }^{1}$ Crisis Resolution and Home Treatment Team, Winchester; ${ }^{2}$ Hampshire Partnership NHS Foundation Trust: ${ }^{3}$ University of Southampton Correspondence to Shanaya Rathod (shanayarathod@nhs.net) First received 13 Apr 2010, final revision 4 Sep 2010, accepted 22 Oct 2010
Aims and method The study explored the impact of National Health Service changes on the working and personal lives of psychiatrists. A questionnaire survey was carried out with psychiatrists working in the South Eastern Division of the Royal College of Psychiatrists.

Results The response rate was $44.9 \%$. Changes to services have reduced stress in some areas, but increased stress in others. Over the past decade early retirement has become less popular, but psychiatrists have been more likely to self-prescribe and have suicidal thoughts.

Clinical implications The increasing involvement of psychiatrists in leadership may be a way to reduce adverse impacts of future changes on their working lives.

Declaration of interest None.
Ten years ago, two papers surveyed sources of stress in UK psychiatrists and were published in this journal. ${ }^{1,2}$ Rathod $e t$ $a l^{2}$ revealed frequent reports of anxiety and depressive symptoms and highlighted serious consequences such as contemplation of suicide or early retirement. In the late 1990s, excessive workloads contributed to premature retirement, which in turn led to consultant shortages. ${ }^{3}$

The past decade has seen changes designed to reduce medical workload and enhance availability of consultants to those most unwell. National changes included New Ways of Working, ${ }^{4}$ new consultant contract, modernising services leading to creation of functional teams (e.g. crisis resolution and home treatment (CRHT) teams), Modernising Medical Careers, ${ }^{5}$ and controversial changes to the National Health Service (NHS) and the Mental Capacity Act. ${ }^{6}$ These changing patterns of the NHS have attracted considerable criticism $^{7}$ and may have imposed greater stresses on doctors. Psychiatrists have been found to be more vulnerable to burnout than physicians and surgeons. ${ }^{8}$ Our study aimed to examine the impact of those changes on the working and personal lives of psychiatrists.

\section{Method}

\section{Measurement and sample}

The Stress Questionnaire from the Rathod et $a l^{2}$ study was adapted for the purpose of our survey. Section 1 recorded demographic characteristics and added a question about ethnicity. Section 2 was expanded to reflect national changes in the NHS over the past 10 years. Variable degrees of stress were measured using a Likert rating scale of 1-6 that included 'not applicable' and 'reduced stress' options.
Sections 3-5, measuring negative and positive coping strategies, as well as physical and emotional impact of stress, remained unchanged. A Likert rating scale of 1-5 scored the frequency of a coping mechanism or symptom. Section 6 asked about life choices, requiring a 'yes/no' response, as in the original questionnaire. All questions, except for demographic characteristics, referred to the past 6 months.

The sample comprised all psychiatrists working in the South Eastern Division of the Royal College of Psychiatrists between June and September 2009. Approximately 1100 members were contacted by email via the College database; the email included a link to the Stress Questionnaire. Confidentiality and anonymity were assured. Questionnaires could be returned via email or post. Return rates were enhanced by distribution and collection at conferences, academic meetings and courses.

\section{Statistical analysis}

Descriptive statistics and $\chi^{2}$-analysis examined the relationship between variables. Data were analysed using SPSS version 18 for Windows. Demographic factors were converted into binary categories. Age was split into below and above 35. Job title was categorised into seniors (consultants, associate specialists and specialty doctors) and juniors (all others grades). Ethnicity was divided into White and Other (Asian, Black, mixed, Chinese and Other). Marital status categorised those with a partner (married or living with partner) and those without a partner (single, divorced, separated or widowed). Time spent in the UK (overseas graduates) and in psychiatry used a cut-off of 5 years. 


\section{Results}

\section{Demographic characteristics}

Out of 1100 emails sent, approximately 100 emails were undelivered because the email addresses were out of date. We received 449 responses (response rate $44.9 \%$ ). Almost half of the sample $(48.8 \%)$, but $53.6 \%$ of consultants, were male; $63.4 \%$ of the respondents were senior psychiatrists: consultants (46.5\%), associate specialists (9.6\%) and specialty doctors (7.3\%). Most described themselves as career psychiatrists (84.1\%). The majority were above 35 years old $(72.3 \%)$ and had a partner (85.2\%). As regards ethnicity, $60.3 \%$ of respondents were White $(70.8 \%$ of consultants); $58.5 \%$ were UK-qualified ( $66.5 \%$ of consultants) and $71.4 \%$ had worked more than 5 years in psychiatry.

\section{Sources of reduced and high stress}

The top five areas of reduced stress, which shared similar results for the entire sample and consultants, are shown in Table 1.

The top ten sources of high stress (percentage of moderate to extreme stress) differed for all grades and consultants, as illustrated in Table 2.

\section{Coping strategies and physical/emotional impact}

The most frequent positive and negative coping strategies (rated as used often and very often) for all grades and consultants are ranked in Table 3.

Rankings of physical and emotional impact (occurrence rated as often and very often) highlighted tiredness (32.4\%, $n=144)$ and headaches $(16.5 \%, n=73)$ as the most frequent symptoms for all grades of psychiatrists. Findings were similar for consultants (tiredness $29.8 \%(n=62)$, headaches $14.1 \%(n=29))$

\section{Life changes in response to stress}

Table 4 shows the percentage of respondents who answered 'yes' to considering a particular life decision.

A $\chi^{2}$-analysis of the six outcomes (Table 4) across demographic groups revealed that life decisions were not associated with gender or place of qualification. Seriously considering a change of job was significantly associated with senior grade $(P=0.034)$, age over $35(P=0.018)$ and spending

\begin{tabular}{llr} 
Table 1 & \multicolumn{2}{c}{$\begin{array}{l}\text { Top five aspects of work causing reduced stress } \\
\text { for psychiatrists }(n=449)\end{array}$} \\
\cline { 2 - 3 } & All grades & Consultants \\
\hline 1 Creation of functional teams & $86(26.4)$ & $33(21.4)$ \\
\hline 2 CRHT teams as gatekeepers & $79(23.8)$ & $27(19.0)$ \\
\hline 3 Working in multidisciplinary teams & $66(14.9)$ & $33(15.9)$ \\
\hline 4 Generic/nurse-led services & $52(14.0)$ & $32(18.5)$ \\
\hline 5 In-patient/community roles created & $33(10.9)$ & $16(11.7)$
\end{tabular}

$\mathrm{CRHT}$, crisis resolution and home treatment. over 5 years in psychiatry $(P=0.046)$. Plans for retiring early was also highly associated with the same three demographic categories ( $P=0.000$ for each group).

A similar result was seen with consideration of selfprescribing medication being associated with seniors $(P=0.002)$, age over $35(P=0.017)$ and over 5 years of psychiatric experience $(P=0.025)$. When consultants were analysed against other grades, retiring early was the only significant outcome associated with this group $(P=0.002)$.

Other significant findings included having seriously considered a change of job being associated with career psychiatrists $(P=0.029)$ and considering a change of specialty being associated with having no partner $(P=0.026)$. Being of Black and minority ethnic origin was also a factor in considering a specialty change $(P=0.002)$, nearly significant for self-prescribing $(P=0.053)$, but significant in considering suicide $(P=0.011)$.

\section{Discussion}

The sample in our study was 449 (44.9\% response rate), compared with 76 (62\% response rate) in the Rathod et al ${ }^{2}$ study. This response is encouraging for a lengthy questionnaire covering a large sample of NHS trusts in nine counties, compared with a smaller sample size of the previous study. Ethnicity data, omitted in the earlier study, revealed that approximately $60 \%$ of doctors were White, and this figure was higher (over two-thirds) among consultants. Other key demographic characteristics were comparable between the two studies. Gender distribution was roughly equal in both studies. Seniors predominated both in the present (62.5\%) and the previous (55\%) study, hence trainees may have been underrepresented. In the current sample, most respondents $(71.4 \%)$ had worked in psychiatry for over 5 years, which is a similar proportion to

Table 2 Top ten aspects of work causing moderate to extreme stress for all grades and consultants

$n(\%)$

All grades
1 CT/ST applications
2 Sickness of children
3 Prospect of future consultant post
4 Training $v$. service needs
5 Arranging child care
6 Job interfering with family life
7 Keeping up with NHS changes
8 Loss of continuity of care
9 Working across interfaces
10 Conflict with managers

$37(52.9)$

$94(46.5)$

$130(46.1)$

$173(45.3)$

$91(44.2)$

$187(43.5)$

$177(43.4)$

$157(43.2)$

$168(41.2)$

$158(40.8)$

\section{Consultants}

1 Working across interfaces

$95(49.3)$

2 Conflict with managers

3 Need to delegate work to team members 86 (46.0)

4 Loss of continuity of care

$70(43.5)$

5 Job interfering with family life

$85(42.3)$

6 Keeping up with NHS changes

$82(42.1)$

7 Sickness of children

$47(40.2)$

8 Education/training demands

$71(37.3)$

9 Training $v$. service needs

$64(36.5)$

10 Arranging child care

$\mathrm{CT}$, core trainee; NHS, National Health Service; ST, specialty trainee. 


\begin{tabular}{|c|c|}
\hline \multicolumn{2}{|c|}{$\begin{array}{l}\text { Table } 3 \text { Top five positive and negative coping } \\
\text { strategies identified by study participants }\end{array}$} \\
\hline & $n(\%)$ \\
\hline \multicolumn{2}{|l|}{ All grades } \\
\hline \multicolumn{2}{|l|}{ Positive coping strategies } \\
\hline 1 Seeking support & $231(52.1)$ \\
\hline 2 Watching TV or going to the cinema/theatre & $186(42.0)$ \\
\hline 3 Exercising & $155(35.2)$ \\
\hline 4 Socialising & $113(25.5)$ \\
\hline 5 Managing time better & $99(22.6)$ \\
\hline \multicolumn{2}{|l|}{ Negative coping strategies } \\
\hline 1 Worrying & $229(51.2)$ \\
\hline 2 Going on as if everything was fine & $170(38.1)$ \\
\hline 3 Driving self harder & $126(28.2)$ \\
\hline 4 Being anxious & $125(28.0)$ \\
\hline 5 Losing sleep & $112(25.1)$ \\
\hline \multicolumn{2}{|l|}{ Consultants } \\
\hline \multicolumn{2}{|l|}{ Positive coping strategies } \\
\hline 1 Seeking support & $102(49.3)$ \\
\hline 2 Exercising & $81(39.7)$ \\
\hline 3 Watching TV or going to the cinema/theatre & $88(37.7)$ \\
\hline 4 Socialising & $44(21.3)$ \\
\hline 5 Confiding in colleagues & $41(19.7)$ \\
\hline \multicolumn{2}{|l|}{ Negative coping strategies } \\
\hline 1 Worrying & $96(45.9)$ \\
\hline 2 Going on as if everything was fine & $80(38.3)$ \\
\hline 3 Driving self harder & $65(31.1)$ \\
\hline 4 Losing sleep & $54(25.8)$ \\
\hline 5 Being anxious & $52(24.9)$ \\
\hline
\end{tabular}

that in the original study (73\%) and implies that the majority were well settled in psychiatry.

\section{Ranking of sources of stress}

The most frequent areas of reduced stress were creation of functional teams, CRHT as gatekeepers, working in multidisciplinary teams, introduction of generic/nurse-led services, and creation of separate in-patient and community roles. This demonstrates how modernisation of mental health service delivery has reduced stress. Crisis resolution home treatment teams were a top source of lowering stress, which is consistent with their role in taking over the acute management of patients and as decision makers in admitting patients to in-patient units.

Generic and nurse-led assessments, as well as partitioning of in-patient and out-patient duties, have also reduced stress. Separating in-patient and community roles

\begin{tabular}{|c|c|c|}
\hline \multirow[b]{2}{*}{ I have seriously considered . . . } & \multicolumn{2}{|c|}{$n(\%)$} \\
\hline & All grades & Consultants \\
\hline Change of job & $225(50.8)$ & $107(51.9)$ \\
\hline Change of specialty & $116(26.2)$ & $49(23.7)$ \\
\hline Retiring early & $201(45.3)$ & $110(52.9)$ \\
\hline Leaving medicine & $175(39.6)$ & $78(37.9)$ \\
\hline Suicide & $66(14.9)$ & $31(15.0)$ \\
\hline Self-prescribed medication & $73(16.5)$ & $37(18.0)$ \\
\hline
\end{tabular}

may allow consultants to be dedicated to a single aspect of care and avoids them being distracted by other issues or having too many areas to cover. ${ }^{9}$ It may also account for why working in a multidisciplinary team was identified as one of the top sources of reduced stress.

The introduction of functional teams may have also created challenges - working across interfaces and loss of continuity of care were ranked by psychiatrists as highstress. In a survey of psychiatrists' attitudes to New Ways of Working, ${ }^{10} 73.5 \%$ stated that those measures would lead to lack of continuity of care and less than a quarter perceived their working lives as improved. Concerns about monitoring individuals with complex needs across all service interfaces have also been raised. ${ }^{11}$

The sources of high stress for all psychiatric grades included concerns about future consultant posts and applying for jobs in connection with the introduction of Modernising Medical Careers (Table 2). The latter has attracted criticism of late that focused on the weighting and marking of applications. Sickness of children and arranging child care were also among the top five stressors. Child care issues reflect the increasing difficulties doctors experience in achieving a balance with their family lives.

Consultants' perception of high-stress areas differed from that of the entire sample. This is consistent with their increasing focus on service and management issues. Stressful areas included working across interfaces, conflict with managers, delegation of work, loss of continuity of care, and rapid changes in the NHS. Consultants also reported stress about the needs and demands of training in the context of service development. Child care issues were a high source of stress for consultants, but less than for the whole sample, probably because consultants are likely to have older children.

\section{Ranking of coping strategies and physical/emotional symptoms}

Positive coping strategies most popular among psychiatrists included seeking support, confiding in colleagues and socialising (Table 3). This shows an appreciation of the psychosocial means of managing stress. Social support was the top coping strategy as a buffer against stress; exercise and entertainment were also helpful aspects of coping with stress.

Doctors used negative coping strategies such as worrying, attempting to show resilience by carrying on as if everything was fine and driving themselves harder. Anxiety and losing sleep, symptoms that have impact on one's mental health, were also among the top negative coping methods.

Tiredness and headaches were the most common physical symptoms reported, with the former being consistent with Rathod et al's ${ }^{2}$ study findings. Tiredness and somatic symptoms are significant because they are dimensions of emotional exhaustion that is a component of burnout. $^{8}$

\section{Life choices}

Approximately half of the sample had seriously considered a change of job and $26 \%$ had considered a change of specialty. 
This is a concern with respect to recruitment and retention difficulties in psychiatry. ${ }^{12}$ Even more worrying is that nearly $40 \%$ of doctors had seriously considered leaving medicine, $5 \%$ more than in the Rathod et $a l^{2}$ study. Furthermore, $15 \%$ of doctors considered suicide and $17 \%$ self-prescribed medication, which is higher than what had been found in the original study ( $11 \%$ and $10 \%$ respectively).

Doctors who spent more time in psychiatry (seniors, those over 35 and those working more than 5 years in psychiatry) had seriously considered a change of job, early retirement and self-prescribing. This may be related to some aspects of working in psychiatry, such as 'the most intense form of interpersonal contact with patients ${ }^{1}$ that builds up over time. These stressful aspects of working in psychiatry can have serious consequences on one's career, including premature retirement. $^{3}$

Changing specialty was a life choice more likely to be considered by those with no partner, perhaps because their career is less restricted by family considerations. This life choice was also more frequent in doctors from Black and minority ethnic background. Participants from this group were more likely than White doctors to have seriously considered suicide.

\section{Comparison with 10 years ago}

A comparison can be made with the Rathod et $a l^{2}$ paper, in which working conditions were frequently cited as a high source of stress (e.g. on-call duties, working hours, dealing with patients' relatives, paperwork, admissions). In contrast, the present study revealed service issues (working across interfaces, rapid NHS changes, loss of continuity of care), life-work balance (sickness of children, arranging child care, family life) and training issues (job applications, consultant posts, service/training demands) as frequent sources of stress. The physical effects of stress have not changed, with tiredness being the most common complaint in both surveys.

The effect of stress on life choices was comparable with the previous survey. However, plans for early retirement were more popular 10 years ago $(51 \%)$ than in the present survey (45\%). This may reflect the fact that early retirement was applicable to more psychiatrists in 2000 , because since 1995 the mental health officer status that allows for early retirement is not applicable to new entrants. Another change that has occurred in the past 10 years is the increase in those considering suicide (from 11 to $15 \%$ ) and those selfprescribing medication (from 10 to $17 \%$ ).

\section{Limitations}

The principle limitation of our study is that despite a large sample size that gives an overall margin of error of $3.43 \%$, which in itself is adequate, there are many subdivisions to the total response (of 449) brought about by the individual questions. For example, 281 consultants out of the population of 1000 gives a margin of error of 4.96. This is acceptable, but with further subdivisions the margin of error increases. The reader needs to interpret the findings in light of this limitation.

The findings of anxiety, insomnia and physical symptoms are not directly comparable with another population, as a specific screening tool such as the General Health Questionnaire or Maslach Burnout Inventory was not used.

The survey did not explore whether doctors worked in hospital or community services, which is relevant as it entails different types of stress. ${ }^{13}$ Information on which subspecialties the doctors worked in was also omitted; this would have been useful to allow comparison with other studies (e.g. old age psychiatrists score highly on emotional exhaustion). ${ }^{14}$

\section{Implications}

The present study has shown that some of the changes implemented in the NHS, for example creation of functional teams, have reduced stress in psychiatrists. On the other hand, increased stress through service changes and in areas of life-work balance, particularly child care issues, has been striking. Another area of major concern and one needing further investigation is the increase in suicidal thoughts among psychiatrists.

Whereas the previous survey showed working conditions as a source of stress, our survey shows that service changes, which were indeed designed to address the above problems, are themselves areas of stress. However, it is the authors' opinion that it is the consequences of these changes such as lack of continuity of care that are causing the stress rather than the changes per se.

Further research is needed on how these changes have affected patient experience. It is also important that doctors become involved in leadership in a wider context. Doctors ought to be seen as a leading force for improving safety, quality and service through innovation, communication and resilience so that any future service reorganisation does not become a source of further stress for psychiatrists.

\section{Acknowledgements}

Since submitting this paper $\operatorname{Dr}$ Ben lbbotson has sadly passed away. We are grateful for Dr Ibbotson's contribution to this project. We thank all members of the South Eastern Division who responded to our survey; authors of the original paper; members of South Eastern Division Executive Committee; and Dr Avleen Sawhney, Dr Sohan Derasari, Dr Farooq Naeem, Dr Seshagiri Rao Nimmagadda, Dr Steve Brown, Dr Roger Palmer, Dr Jim Ormsby, Ms Val Seagroatt.

\section{About the authors}

Shanaya Rathod is consultant psychiatrist and associate medical director, Crisis Resolution and Home Treatment Team, Winchester; Minal Mistry is specialist registrar in adult psychiatry and Ben Ibbotson is honorary research assistant, Hampshire Partnership NHS Foundation Trust; David Kingdon is Professor of Mental Health Care Delivery, University of Southampton.

\section{References}

1 Guthrie E, Tattan T, Williams E, Black D, Bacliocotti H. Sources of stress, psychological distress and burnout in psychiatrists. Comparison of junior doctors, senior registrars and consultants. Psychiatr Bull 1999; 23: 207-12. 
2 Rathod S, Roy L, Ramsay M, Das M, Birtwistle J, Kingdon D. A survey of stress in psychiatrists working in the Wessex Region. Psychiatr Bull 2000; 24: 133-6.

3 Kendell RE, Pearce A. Consultant psychiatrists who retired prematurely in 1995 and 1996. Psychiatr Bull 1997; 21: 741-5.

4 Department of Health. New Ways of Working for Psychiatrists: Enhancing Effective, Person-Centred Services through New Ways of Working in Multidisciplinary and Multiagency Contexts. Department of Health, 2005.

5 Department of Health, Scottish Executive, Department of Health, Social Services and Public Safety, Welsh Assembly Government. Modernising Medical Careers: The Next Steps. Department of Health, 2004.

6 Hall I, Ali A. Changes to the Mental Health and Mental Capacity Acts: implications for patients and professionals. Psychiatr Bull 2009; 33 226-30.

7 St John-Smith P, McQueen D, Michael A, Ikkos G, Denman C, Maier M, et al. The trouble with NHS psychiatry in England. Psychiatr Bull 2009, 33: $219-25$.
8 Kumar S. Burnout in psychiatrists. World Psychiatry 2007; 6: 186-9.

9 Ingram G, Tacchi MJ. Service innovation in a heated environment: CATS on a hot tin roof. Psychiatr Bull 2004; 28: 398-400.

10 Dale J, Milner G. New Ways not working? Psychiatrists' attitudes. Psychiatr Bull 2009; 33: 204-7.

11 Kennedy P, Griffiths $\mathrm{H}$. What does 'responsible medical officer' mean in a modern mental health service? Psychiatr Bull 2002; 26: 205-8.

12 Pidd SA. Recruiting and retaining psychiatrists. Adv Psychiatr Treat 2003; 9: 405-11.

13 Sorgaard KW, Ryan P, Hill R, Dawson I. Sources of stress and burnout in psychiatric care: inpatient vs. community staff. Soc Psychiatry Psychiatr Epidemiol 2007; 42: 794-802.

14 Benbow SM, Jolley D. Burnout and stress amongst old age psychiatrists. Int J Geriatr Psychiatry 2002; 17: 710-4. 